\title{
Non cannulated intramedullary nailing in treatment of nonunited tibial fractures
}

Accepted: $25 / 9 / 2011$

\begin{tabular}{c}
\hline Yousif Rashid Mohammad * \\
\hline Abstract
\end{tabular}

Background and objectives: Nonunion following diaphyseal tibial fractures is still a challenging problem facing orthopaedic practice, different approaches used to tackle this problem , the aim of this study was to evaluate the outcome of treatment by non cannulated intramedullary nailing as regards union and complications

Method: Eighteen patients with non-united diaphyseal tibial fractures their age ranged between 19-60 years (mean of 33.5 years) were studied and treated by non cannulated intramedullary nailing between 2005 to 2010. Initially all these patients underwent multiple surgeries including wound excisions, revision of fixation and bone grafting All underwent fixation by non cannulated intramedullary nailing, in 14 patients, the site of the non-union wasexplored to correct alignment by osteotomy, while closed intramedullary nailing were performed in the remaining 4 patients

Results: In seventeen cases ( $94.4 \%$ ) union was achieved between 5 - 9 months with an average of 7.5 months, complications included refracture and failure of fixation in 1 patient ( $5.6 \%$ ) and superficial wound infection occurred in 3 cases ( $16.6 \%$ )Patients with nonunited diaphyseal fractures were followed post-operatively for $1-6$ year( average 4 years ), eventually healing was successful with full weight bearing without support and pain , fracture line was not visible on radiographs

Conclusion: Non-cannulated intra-medullary nailing appears to be very helpful procedure to promote union in these cases with relatively less significant complications .

Keywords: Non cannulated intramedullary nail - Nonunion tibial diaphyseal fractures

\section{Introduction}

Nonunion diaphyseal tibial fractures are still a challenging complication facing Orthopaedic surgeons particularly following open tibial fractures, Gustilio type 2 and 3 ,cases with segmental fractures and comminuted fractures associated with bone loss and complicated by chronic Osteomyelitis add more to this difficulty. Different surgical techniques are used in treatment including cannulated intramedullary nailing,less invasive plating technique, illizarov, vascularize bone graft etc ${ }^{1-10}$ The aim of this study is to evaluate the outcome of treatment by non cannulated intramedullary nailing as regards union and complications.

\section{Method}

Eighteen patients with nonunited diaphyseal tibial fractures were treated by non cannulated intra-medullary nailing from 2005 to 2010 There were 16 men $(88.8 \%$ ) and 2 women $(11.11 \%)$ with involvement of the involvement of the left side in 10 cases ( $55.5 \%)$ and right in $8(44.4 \%$ ) The anatomical locations were involving upper third in 4 patients ( $22.2 \%$ ), mid shaft in 6 cases ( $33.3 \%)$ ) and lower third in 8 $(44.4 \%)$, it was hpertrophic nonunion in 4 cases ( $22.2 \%$ ), atrophic in $12(66.6 \%)$ and infected in 2 patients $(11.11 \%)$ The average age was 33.5 years (ranged between 19 - 60 years ), duration of non-union varied between $2-4$ years at

*Department of Surgery, College of Medicine, Hawler Medical University, Erbil, Iraq 
presentation .All had been operated previously by multiple surgery including several wound debridements, external fixation and plating Open nailing performed in 14 patients, in these patients the nonunion site was involving the mid-shaft of tibia in 6 patients and lower $3^{\text {rd }}$ in 8 patients, tibial osteotomy was necessary to realign the fracture and removal of all dead sclerotic bone from both ends of the bone at the nonunion site, the medullary canal was opened proximally and distally by using only one or two small calibre reamer The nail was introduced without reaming, size of nail was chosen to fit well in the medullary canal to improve stability of the bone-implant complex, locking done proximally and distally in 12 cases Intramedullary nailing was successful in treating 2 patients with infected nonunion as no active infection was present at time of surgery Antibiotic was chosen accordingto culture and sensitivity, cefotaxime vials of $1 \mathrm{gm}$ dose was given intravenously twice daily for 6 days followed by ciprofloxacin capsule $500 \mathrm{mg}$ given orally twice daily for 6 weeks In 4 patients with hypertrophic nonunion involving upper 3 rd of tibia, closed intramedullary nailing was used under fluoroscopy guide and only proximal locking were done Autogenous bone graft from the iliac crest was used in 12 cases with atrophic nonunion Fibular osteotomy was not done unless it was Iready damaged by previous surgery, the fibula was already resected in 6 cases because of previous subsequent surgeries Post operatively, partial weight bearing was started after six weeks. Thereafter, weight-bearing was allowed according to progress of union as assessed by clinical and radiological examinations based on the absence of pain and the appearance of callus during the period of follow up at monthly interval . Patients were followed for 2-6 years, all patients showed complete bone healing and consolidation after 2 years post operatively. Only in 1 case the follow up period was one year this patient start full weight bearing without support and union was confirmed clinically and radiologically.

\section{Results}

Healing were assessed as regards clinical examination including absence of pain and tenderness and by radiological signs of satisfactory consolidation at the fracture site. In seventeen patients ( $94.4 \%)$ showed satisfactory union, healing period ranged between 5-9 months ( average of 7.5 months ) .Complications was encountered in 1 patient $(5.5 \%)$ with bending of the nail, refracture of the lower $3^{\text {rd }}$ of the tibia with severe comminution of the posterior cortex above the ankle joint after severe fall which was solved by application of compression plate and autogenous bone grafting. Superficial wound infections were encountered in 3 cases (16.6\%) and no deep infection occurred in these patients . Bone Healing after Intramedullary nail fixation for non-union diaphyseal tibial fracture, the proximal locking screws removed 2 months after surgery to allow axial compression by partial weight bearing. Post operative x-rays for two patient underwent locked intramedullary nailing for nonunion tibial diaphyseal fracture. 

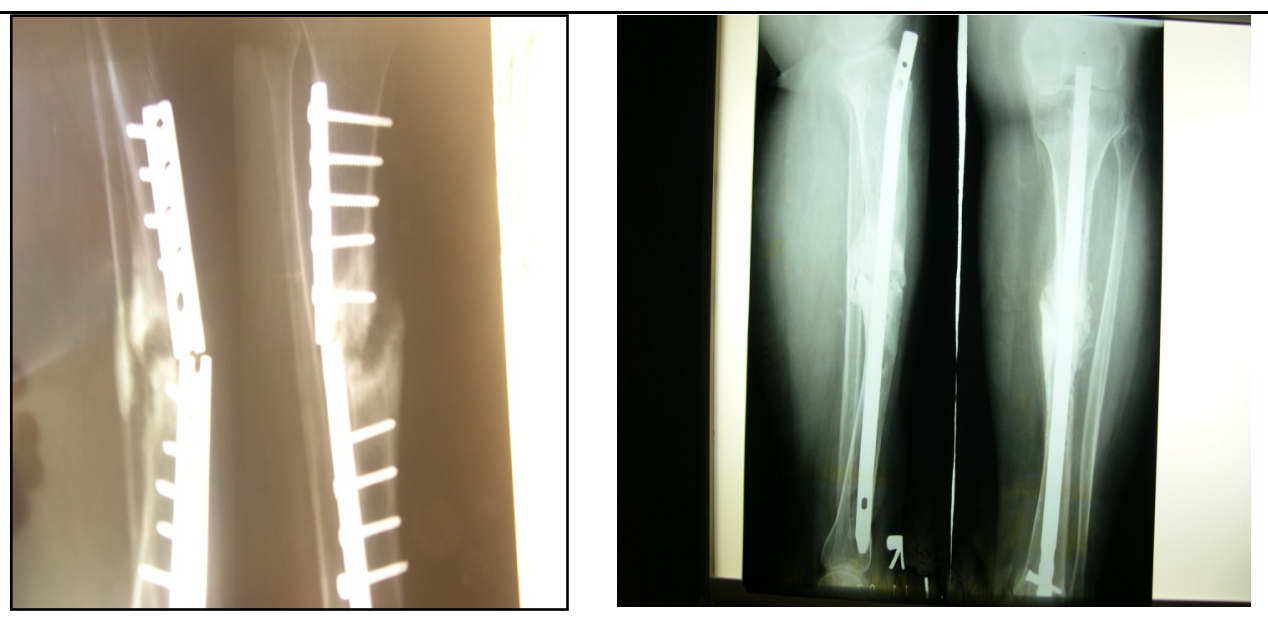

Figure 1: ( $A, B)$
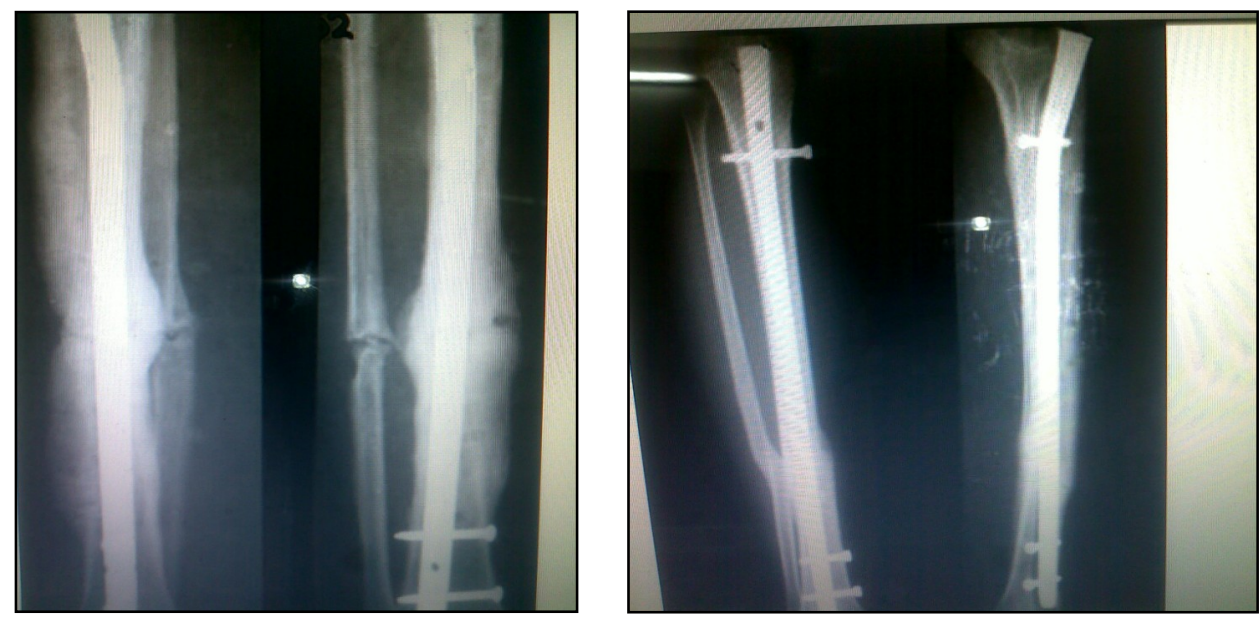

Figure 2: ( $A, B)$

\section{DISCUSSION:}

Non-union of the tibial shaft is a common problem, treatment may require multiple operative procedures and years of disability before union is obtained. Several surgical procedures have been advocated for the treatment of non-union of diaphyseal fractures of the tibia ,these includes Interlocking intramedullary nailing, free vascularized fibular grafts, the llizarov technique of corticotomy and bone transport , posterlateral cancellous bone grafting and other techniques for creating tibio-fibular synostosis. ${ }^{1-3,11}$ In this study non reamed intramedullary nailing were used for treatment, open nailing technique were applied in 14 cases, during surgery it was necessary to perform corrective osteotomy with complete excision of soft tissue interposition and sclerotic a vascular bone ,this procedure described in other studies. 7,12,13 It is considered by many authors that reamed intramedullary nailing has been accepted widely as an effective method of treatment for atrophic and hypertrophic types of diaphyseal tibial nonunion with high rate of union, low incidence of complications and excellent functional results. $4-6,8,14$ 
Closed intramedullary nail was applied for treatment in 4 patients with proximal diaphysis tibial nonunion, proximal locking was necessary to prevent complications like varus or valgus angulation. ${ }^{9}$ Closed Intramedullary nailing technique gives excellent result because it will not jeopardize the normal anatomy of the soft tissue and muscle attachment around the fracture site, thus encourage biological healing of fractures and reducing complications like infection $7,8,15,16$. Resection of fibula was done previously in 6 cases, in the remaining 12 cases the fibula was intact, in this study, it was found that fibular resection has no influence on union time. Debate still present between surgeons on value of fibular resection in treatment of nonunion

\section{Conclusion}

Non Cannulated Intramedullary nailing technique is effective with good functional results in treating patients with nonunited tibial diaphyseal fractures. The complications including deep infection is relatively lower in patients treated with intramedullary nailing. Closed intramedullary nailing has additional advantage in the treatment of nonunion diaphyseal tibial fractures because it will not affect soft tissue envelope around the bone and it is helpful in management of this problem .

\section{References}

1. Chacha PB, Ahmed M, Daruwalla JS; Vascular pedicle graft of the ipsilateral fibula for nonunion of the tibia with a large defect, $J$ Bone Joint Surg 63A; 244, 1981.

2. Marsh DR, Shah S, Elliott J, et al; The ILizarov method in non-union, malunion, and infection of fractures , J Bone Joint Surg 79B; $273,1997$.

3. Schwartsman V, Choi SH, Schwartsman R. Tibial nonunions. Treatment tactics with the llizarov method. Orthop Clin North Am. 1990;21:639 -53.

4. Court-Brown CM, McQueen MM, Quaba AA, Christie J. Locked intramedullary nailing of open tibial fractures. J Bone Joint Surg Br. 1991;73:959 $-64$.

5. Clancey GJ, Winquist RA, Hansen ST Jr. Nonunion of the tibia treated with Kuntscher intrame dullary nailing.Clin Orthop Relat Res .1982; 167:191-6.

6. Court-Brown CM, Keating JF, Christie J, McQueen MM. Exchange intramedullary nailing. Its use in aseptic tibial nonunion. J Bone Joint Surg Br.1995; 77:407 -11.

7. McLaren AC, Blokker CP ; Locked intramedullary fixation for metaphyseal malunion and nonunion, Clin Orthop Relat Res 265:253, 1991.

8. Sledge SL, Johnson KD, Henley MB, Watson JT. Intramedullary nailing with reaming to treat nonunion of the tibia.J Bone Joint Surg Am .1989; 71:1004 -19.

9. Lang GJ, Cohen BE, Bosse MJ, Kellam JF. Proximal third tibial shaft fractures. Should they be nailed? Clin Orthop Relat Res. 1995;315:64 74.

10. Wu CC, Shih CH, Chen WJ, Tai CL. High success rate with exchange nailing to treat a tibial shaft aseptic nonunion.J Orthop Trauma. 1999;13:33-8.

11. Paley D, Catagni MA, Argnani F, et al: ILizarov treatment of tibial non-unions with bone loss , Clin Orthop Relat Res 241: 146, 1989.

12. Chapman MW. The effect of reamed and nonreamed intramedullary nailing on fracture healing. Clin Orthop Relat Res. 1998;(355 Suppl):S230 -8.

13. Sitter T, Wilson ,J, Browner B. The effect of reamed versus unreamed nailing on intramedullary blood supply and cortical viability. J Orthop. Trauma 1990; 4:232.

14. Mayo KA , Benirschke SK ; Treatment of tibial malunions and nonunions with reamed intramedullary nails, Orthop Clin North Am $21: 715,1990$.

15. Richmond J, Colleran K, Borens O, Kloen P, Helfet DL. Nonunions of the distal tibia treated by reamed intramedullary nailing. $\mathrm{J}$ Orthop Trauma.2004; 18:603-10

16. Court-Brown CM, Keating JF, McQueen MM. Infection after intramedullary nailing of the tibia. Incidence and protocol for management. J Bone Joint Surg Br.1992; 74:770 -4. 